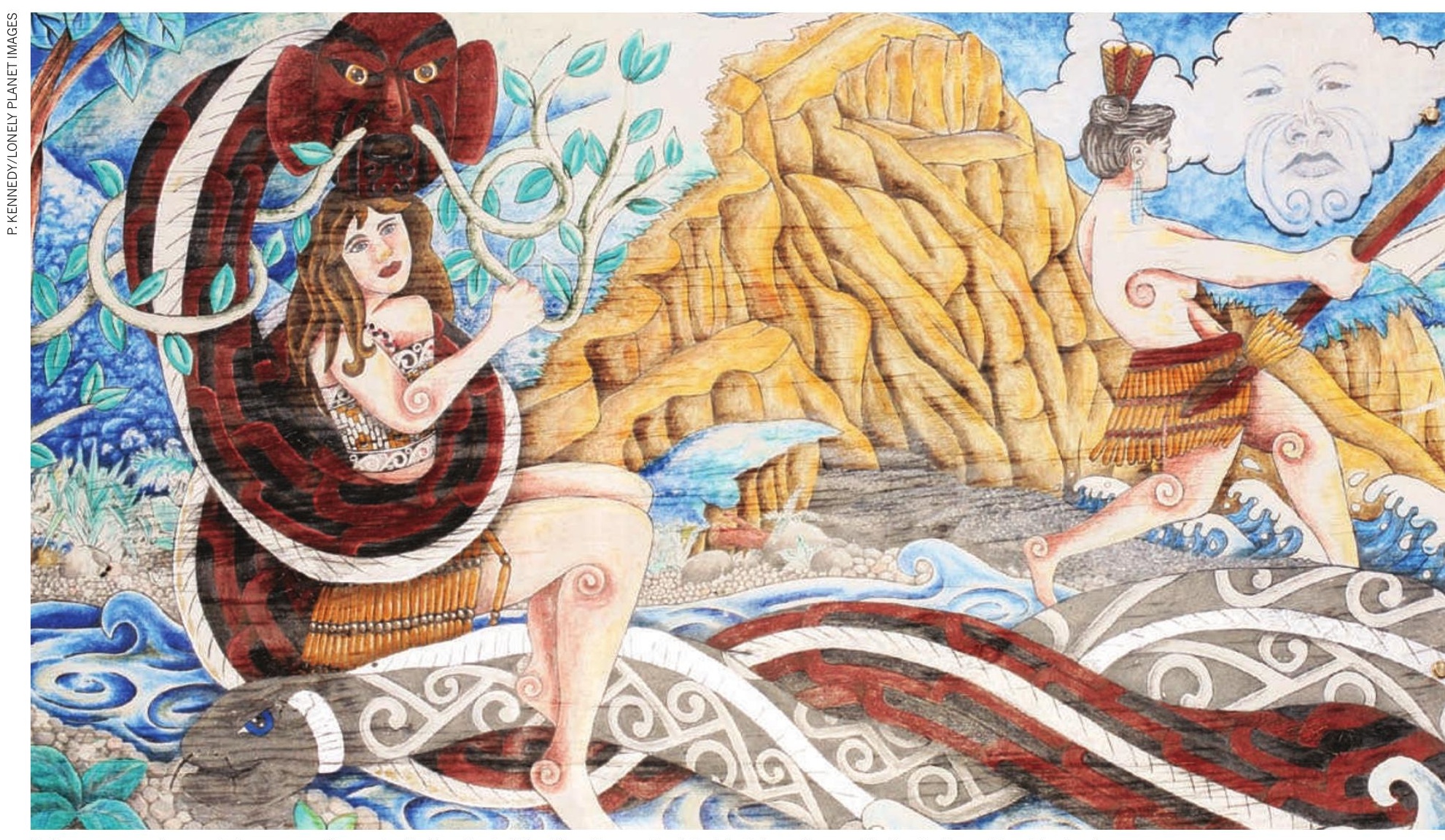

Eels are revered as gods by some cultures, including that of the Maori — as depicted in this wall mural in Canterbury, New Zealand.

\title{
ECOLOGY
}

\section{The mystery of eels}

\section{Kim Aarestrup is reminded of how little we know about these endangered fish.}

$\mathrm{S}$ nake-like and nocturnal, eels are mysterious creatures. They spawn in remote and nutrient-poor places in the seas, and no human has ever seen one reproduce in the wild. Their rice-sized hatchlings embark on an odyssey of up to 6,000 kilometres to find fresh or brackish water, where they grow for decades - reaching weights of more than 20 kilograms - only to return to the sea, where they spawn, die and sink into the abyss.

Exploited as food for millennia owing to their abundance, taste and high energy content, eels cannot yet be cultured profitably. All traded eels are wild - and populations are plummeting. Species in temperate areas, including the American, Japanese and European eel, have become scarce, with populations dropping by more than $90 \%$ in the past four decades. European eels are now listed as critically endangered by the International Union for Conservation of Nature, a shocking development for a fish once found across all the accessible waters of Europe.

In Eels, naturalist James Prosek travels

and interviews leading scientists worldwide to examine the Anguilla genus. By broadening the perspective beyond Atlantic species, his book complements Tom Fort's marvellous The Book of Eels (HarperCollins, 2002). As well as describing the biology of the eel,

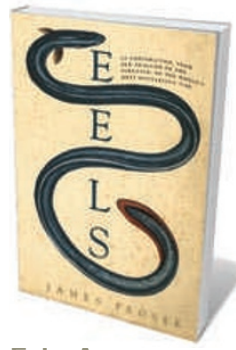

Eels: An

Exploration, from New Zealand to the Sargasso, of the World's Most Mysterious Fish

HarperCollins: 2010. 304 pp. $\$ 25.99$
Prosek considers the cultural and economic value we attach to it, interweaving historic vignettes from Aristotle's interest in the origins of European eels to Sigmund Freud's nineteenth-century search for their testes.

Prosek visits New Zealand, where the Maori revere the large endemic longfin eel Anguilla dieffenbachii as a religious symbol, which they believe can bark like a dog and scream like a baby. Large road projects have been diverted to avoid areas populated by taniwha, or special guardian eels. Prosek goes to Japan, a nation that eats vast quantities of eel, making the traditional dish kabayaki multimillion-dollar industry. $\mathrm{He}$ also visits the Micronesian island of Pohnpei, where Anguilla marmorata is sacred, believed to be the islanders' ancestor.

Restoration of eel populations will be difficult. Prosek lists contributors to their decline: loss of habitat, dams, fishing, introduction of parasites, pollutants and changes in ocean currents. These factors, and our lack of knowledge about key stages of the eel life cycle, make population management problematic.

The plight of temperate species has led to a surge of eel research in the past few years. Recent papers have described captures of Japanese eels that have spawned, showing that they do so in tropical ocean frontal zones, a mixing zone between warm and cold oceanic waters. Other research has revealed the diet of newly hatched eel larvae (called leptocephali) 
